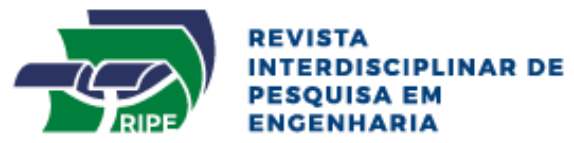

\title{
FEASIBILITY STUDY OF HYBRID THERMOELECTRIC PLANTS USING CSP TECHNOLOGY AND FOSSIL FUEL: SIMULATION SCENARIOS
}

\author{
F. C. de Lisboa $^{1 *}$, A. C. Rodrigues ${ }^{2}$, A. M. G. Cavalcante ${ }^{3}$, M. B. Siqueira ${ }^{4}$, J. Guigné ${ }^{5}$ \\ ${ }^{1}$ Faculdade do Gama- FGA, UNB - St. Leste Projeção A - Gama Leste, Brasília - DF, 72444-240, \\ Brazil \\ ${ }^{124}$ Department of Mechanical Engineering, UnB - Campus Universitário Darcy Ribeiro, Brasília - DF, \\ 70910-900, Brazil ${ }^{3}$ UNICAMP - Cidade Universitária Zeferino Vaz - Barão Geraldo, Campinas - SP, 13083- \\ 970 \\ ${ }^{5}$ Arts et Métiers ParisTech - 151 Boulevard de l'Hôpital, 75013 Paris, France

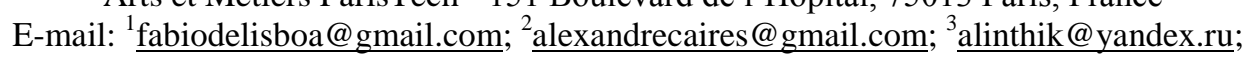

${ }^{4}$ mariosiqueira@unb.br; ${ }^{5}$ julien.guigne@ensam.eu

\begin{abstract}
Due to the rapid advance in technology, a new generation of power plants has emerged: the concentrated solar power (CSP). It is a renewable energy system that can be combined with large-scale energy storage systems. CSP holds many promises for the countries with high direct solar radiation, as Brazil. However, there are many problems regarding the viability of these plants in the emerging countries such as high capital costs, lack of national technology and qualified professionals. Hybridization of existing power plants with solar energy could be a possible gateway for the technology deployment. This paper presents the technical and economic feasibility analysis of a steam super-heater plant powered by CSP for electricity production. Such hybridization permits the reduction of $\mathrm{CO}_{2}$ emissions and retrenchment in the long term. In this context, the performances of four different systems of thermoelectric power generation were compared: (i) solar reheating superheated steam generated by boiler and it expansion in the first turbine using CSP for reheating second expansion turbine; (ii) solar superheater - generating saturated steam in a boiler and superheating it using CSP; (iii) supercritical solar heater - saturated steam production in a boiler and heating at supercritical steam in CSP and (iv) conventional cycle and CSP working in parallel. The direct irradiation data available at the Brazilian solar atlas were analyzed, looking for the best location of power plant installation. In addition to the solar resource data, other criteria as economic, environmental and availability of transmission lines were taken into account. The decision matrix with performance indicators helped in the decision-making process of location selection. Comparing to others scenarios the obtained results showed several advantages of scenario (iv) - conventional cycle and CSP working in parallel using solar power towers without thermal storage. Research result as well revealed Santa Maria da Vitória town, Bahia region, as a better place for plant construction using the selected scenario. The total capacity was determined to be $30 \mathrm{MWe}$ in accordance with the incentives offered by 481/2012-ANEEL (Brazilian Agency) resolution.
\end{abstract}

Keywords: Concentrated solar power (CSP); Solar irradiation data; Hybrid thermoelectric; Reheating vapor cycle. 


\section{Introduction}

Brazil faces the dual challenge: the exhaustion of hydroelectricity and the increase electrical energy offer without losing its "renewability", a positive aspect of Brazil's energy matrix. Among the solutions to overcome these challenges are the bio-electricity, based on biomass, wind and solar energy. Biomass could be a substitute for fossil fuels, but their demand for land and water may threatens our ability to meet the electricity demand and to feed the growing world population (PERLACK et al., 2005). The use of the wind, even though it has great potential, has the inconvenience of intermittency when connected to the grid. Solar energy has enormous potential and, despite suffering with changes in generation throughout the day, when associated with other technologies may represent cost savings and significant reduction on environmental impacts. The energy that reaches the Earth in one hour is greater than the entire amount consumed by humans in a year (ZHANG et al., 2013a). In this context, the power plants by Concentrated Solar Power (CSP) are a way to harness this abundant solar resource.

In the case of thermoelectricity generation in small and medium scale, different system configurations can be used: steam cycles, gas, solar, and hybrid using two or more resources. Each technology has different advantages and disadvantages depending on the scenario where it is used. Specifically, in the case of power generation using CSP, it may be a way to reduce dependence on fossil fuels and meets the international goals towards reducing $\mathrm{CO} 2$ emissions. A promising form of hybridization between conventional processes is the use of CSP combined with other technologies, such as the ones installed in many plants using fossil fuel burning to produce steam for electricity generation in a Rankine cycle (SORIA et al., 2015). This concept has been studied recently by several authors. Peterseim et al.(PETERSEIM et al., 2014) demonstrated that synergies in the hybridization concept could lead up to $50 \%$ in cost reduction and better dispatchability. Although their analysis was focused on the Australian reality they argue that the conclusions are transferable to other countries. In fact, the first hybrid CSP-Biomass hybrid plant came into operation in 2012 in Spain (EMTE; AMBIENTE, 2010). Hybridization has been research topic in Brazil as well, specially due to Brazilian strong co-generation from ethanol and sugar mills (BURIN et al., 2015). In most of these studies, heat transfer fluid (HTF) where either thermal oil or direct steam generation. Using air as HTF, the case in the present work, can be advantageous especially because of no restrictions in terms of working temperature, which allows the plant to work at higher temperature with efficiency gains. It also provides cost reduction and less environmental risks. 
In order to evaluate the technical and economic feasibility of hybridization between fossil and solar resources, four scenarios were tested combining these two different technologies, with no heat storage. In this work, it was studied ways to minimize fuel consumption and environmental risks in the electricity production for three cities of Brazil. At the end a configuration design to city of choice is presented using the better performance scenario of hybridization.

\section{Electricity Production Using Thermal Power Plants}

Thermal Power plants are one of the most important process industries for engineering professionals. Over the past decades, the power sector is facing a number of critical issues; however, the most fundamental challenge is meeting the growing power demand in sustainable and efficient ways. Power-plant engineers not only manage operation and maintenance of the plant, but, also perform other activities including research and development, ranging from power generation to environmental assessment of power plants.

\subsection{Concentrated Solar Power Plant}

Concentrated solar power (CSP) refers to electricity generation by concentrating solar irradiation reaching a solar field in a small area, called receiver. This receiver contains a heat transfer fluid (HTF) expected to transfer heat to a power cycle, often running steam.

Traditionally, there are four concentrating technologies in use today:

- Parabolic Trough Collector (PTC): an absorber tube is fixed on the focal line of a one-dimension parabolic shape, made of a group of reflectors. They move in tandem with the sun from sunrise to sunset (LLORENTE; ÁLVAREZ; BLANCO, 2001). The absorber tube is a steel tube surrounded by a glass envelope, and vacuum between these two elements.

- Solar Power Tower (SPT), or Central Receiver System (CRS), is made of a field of reflectors (heliostats) concentrating the sunrays onto a receiver in the top of a tower (MÜLLER-STEINHAGEN; TRIEB, 2004). A heat transfer fluid absorbs the heat and transfer it to the heat exchangers of a steam Rankine power cycle.

- Linear Fresnel Reflector (LFR): a linear receiver, fixed on a structure above a field of reflectors, flat or slightly curved mirrors.

- Parabolic Dish Collectors (PDC): the receiver is placed on the focal point of a parabolic dish, concentrating sunrays. There is no need of a HTF, it offers the best 
efficiency of any CSP system, but this technology remains expensive, and neither high power nor hybridization are possible (BARLEV; VIDU; STROEVE, 2011).

Two auxiliary technologies can enhance the performance of a CSP system:

Thermal Energy Storage system (TES): the heat in excess coming from the solar field can be transferred to a transfer fluid between a cold tank and a hot tank. The heat stored in the hot tank can supply the steam power circuit. Short term thermal storage allows the balance of energy supply throughout the day.

Backup System (BS): a fuel backup system aims at regulating the production of energy. CSP plants with a backup system are called hybrid plants. This BS can provide energy to the HTF, to the storage fluid, or to the power circuit. Integrated solar combined cycle plants (ISCC) are integration of a CSP field into a fossil fuel fired power plant, such solar fuel savers have relatively limited investment costs (ZHANG et al., 2013b).

Commercially, PTC is the most developed technology, with a considerable number of operating plants, but outlook for improvements are limited (BARLEV; VIDU; STROEVE, 2011). On the contrary, CRS technology shows promising advances as much as HTF development. Compared with other options, CRS can provide cheaper electricity and better performances due to the following aspects:

- Higher temperatures (up to $1000^{\circ} \mathrm{C}$ ), the large amount of irradiation focused on a receiver $\left(200-1000 \mathrm{~kW} / \mathrm{m}^{2}\right)$ simplifies heat transport, minimizes heat losses (SARGENT, 2003). The whole piping system is concentrated in a central area, which reduces losses, material costs and maintenance.

- Good potential for efficiency improvements (40-65\%) (ROMERO-ALVAREZ; ZARZA, 2007).

- Wide variety of options for integration with fossil fuel plants or hybrid operations.

A typical CRS, or solar tower power, comprises three subsystems: a heliostat field, a solar receiver and the power conversion system. The heliostat consists of numerous controlled mirrors tracking the sun and reflecting the radiation onto the receiver, fixed on the top of a tower. The performance of the CRS is strongly related to the solar field efficiency: heliostat design, field layout, control system. Almost $40 \%$ of total energy losses are attributed to the heliostat field (GOSWAMI; KREITH; KREIDER, 2000). The radiation is converted into heat by the circulation of the HTF in the receiver. The upper working temperature can range from $250^{\circ} \mathrm{C}$ to $1000^{\circ} \mathrm{C}$ (PITZ-PAAL, 2005). The heat is transferred to the power circuit, and thermal energy is finally converted into electricity. 
This conversion can be produced in high efficiency in Rankine cycle, Brayton cycle or combined cycle.

\subsection{Steam Cycles for Electricity Production}

The Rankine cycle consists of:

- Compressing water to high pressure, over several MPa;

- Boiling and superheating steam, at the focal point or using heat exchanger;

- Expanding the steam in one or several turbines, connected to a generator;

- Finally condensing low pressure steam.

Vapor must be sufficiently superheated before expansion in the turbines in order to avoid blade erosion. According to the author (DUNN et al., 2012), the efficiency is higher and costs are lower if the system is large and run at full load. However, a larger turbine requires a large field, which implies increased thermal losses. Consequently, there is a trade-off against turbine size.

Others authors (COELHO et al., 2012) have reached the same conclusions analyzing several possibilities of hybridizing biomass and CRS receiver power plants, and found a concept reducing fuel consumption by $17 \%$ compared with conventional power plant. Works made (ZOSCHAK; WU, 1975) compared seven options of integrating CRS into a $80 \mathrm{MW}$ steam cycle, and they found that the most suitable scheme is using solar heat for both evaporation and superheating.

For maximum efficiency, steam turbine can work at supercritical conditions: steam temperature and pressure exceed the critical point. The phase-change occurs continuously. Studying the effect of thermal conductance and thermal irradiance on the optimal receiver temperature and the efficiency of five Rankine cycles, (MCGOVERN; SMITH, 2012) found that super-critical Rankine cycles are suitable for CRS, and sub-critical cycles for parabolic through power plants.

\subsection{Steam Superheaters}

The production of electricity through steam is only possible if the steam is in the superheated state. The superheaters are tubular exchangers in the form of coils, in order to create large heat transfer surfaces to increase the degree of superheating. In general, the place where the gas flows is warmer. They consist of two collectors, one for saturated steam and one for superheated steam. In some designs, the superheater can be divided into two or more stages. In this case, between stages is inserted into the intermediate 
desuperheater. Temperature in superheaters can reache extremely high values requiring special material to resist thermal degradation, carbon-molybdenum steel or chromemolybdenum.

When they are located in convection zone, they are named convection superheaters. They have the basic characteristic of increasing steam temperature with increasing boiler load. On the other hand, when they are subjected to radiation, they are named radiation superheaters, and with increasing boiler load there is a decrease of the steam temperature.

Superheater can also be decoupled from the boiler, receiving heat from another independent source. In this case the equipment becomes an accessory to the steam line. It works under high pressure, consequently, it needs to comply with the standards for pressure vessels and undergo frequent testing to certify their safety. Figure 2 represents schematically a Rankine cycle with a solar power feeding the superheater.

\section{Materials and Methods}

In order to simulate both economical and thermodynamical metrics two softwares were used: CyclePad (FORBUS; WHALLEY, 1995), to simulate the cycles and their performances, and System Advisor Model (SAM) (NREL; LLC; DOE, 2015), to simulate the operational conditions of hybrid power plant, Both are free of charge (freeware), the first designed for thermodynamic cycle simulation and the later for evaluating the use of renewable resources. Four different scenarios for hybridization configurations were defined. In all scenarios air were used as heat transfer fluid (HTF), at the solar receiver. This is justified by the fact that it supports high temperatures, is abundant and free. It also reduces environmental risks because no oil or molten salt circulates through the plant. Very recently, a first demonstration experimental tower has been operated in Jülich-Germany (PY; AZOUMAH; OLIVES, 2013) using air at $700^{\circ} \mathrm{C}$.

To select the cities for this investigation, two aspects were considered, solar irradiation and installed infrastructure to support a hybrid thermoelectric plant. Satellite derived data of direct normal irradiation (DNI) were used, extracted from SWERA data base, of each locality, and compared to the distance from Brazilian electrical transmission lines.

\subsection{Scenarios Definition}

In order to compare performances of hybrid plants, four configurations using solar energy in addition to fossil fuel were proposed. The first scenario presents a reheating 
cycle where the energy required for reheating is from the sun (Figure 1). It does not use thermal storage and the fluid in the solar devices is the air, such that, when there is no availability of solar radiation, air is heated by fossil fuel. Electricity is produced in two generators coupled to the two steam turbines, working with the settings shown in Figure 1. This configuration cannot run on solar power alone, it always requires fossil fuel.

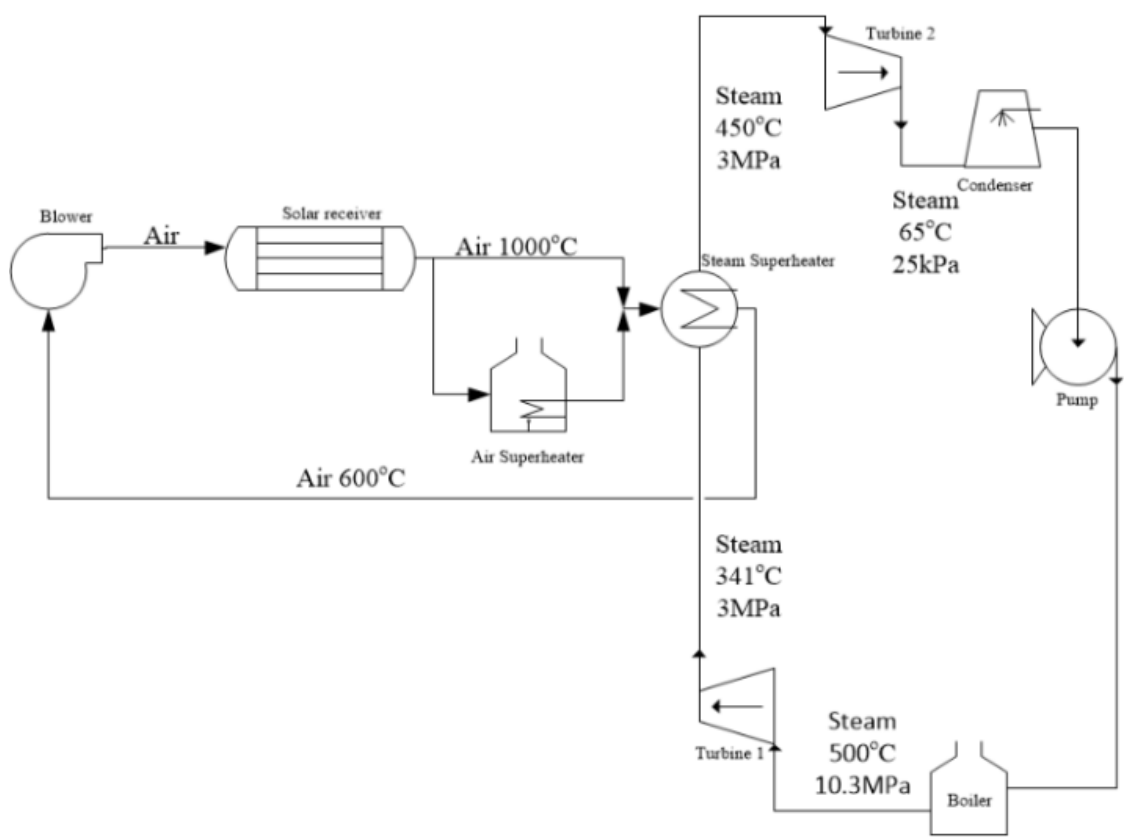

Figure 1. Solar reheating to the second steam turbine. The solar energy is used to reheat steam before the turbine 2.

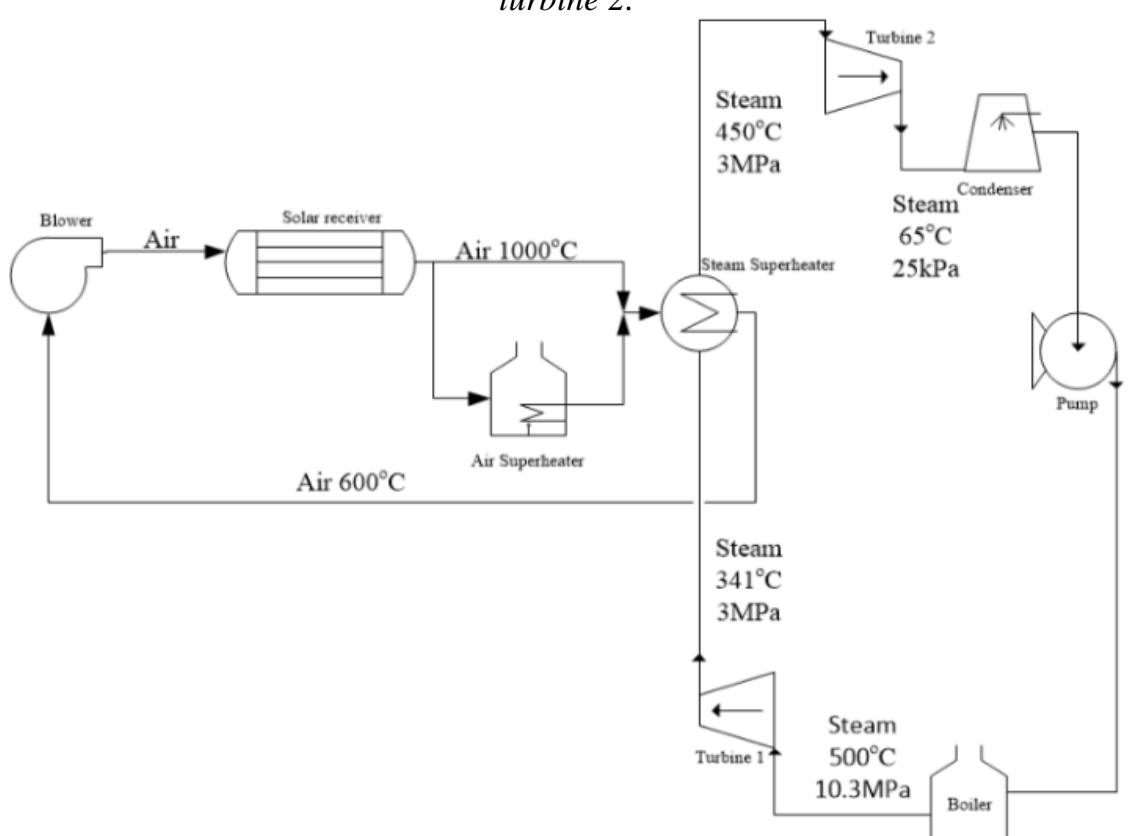

Figure 2. Solar receiver as a steam superheater. Solar energy was used to increase the temperature of steam.

In the second scenario (Figure 2) solar energy was used to superheat saturated steam. As in scenario 1, air is also heated by fossil fuel in the lack of solar irradiation 


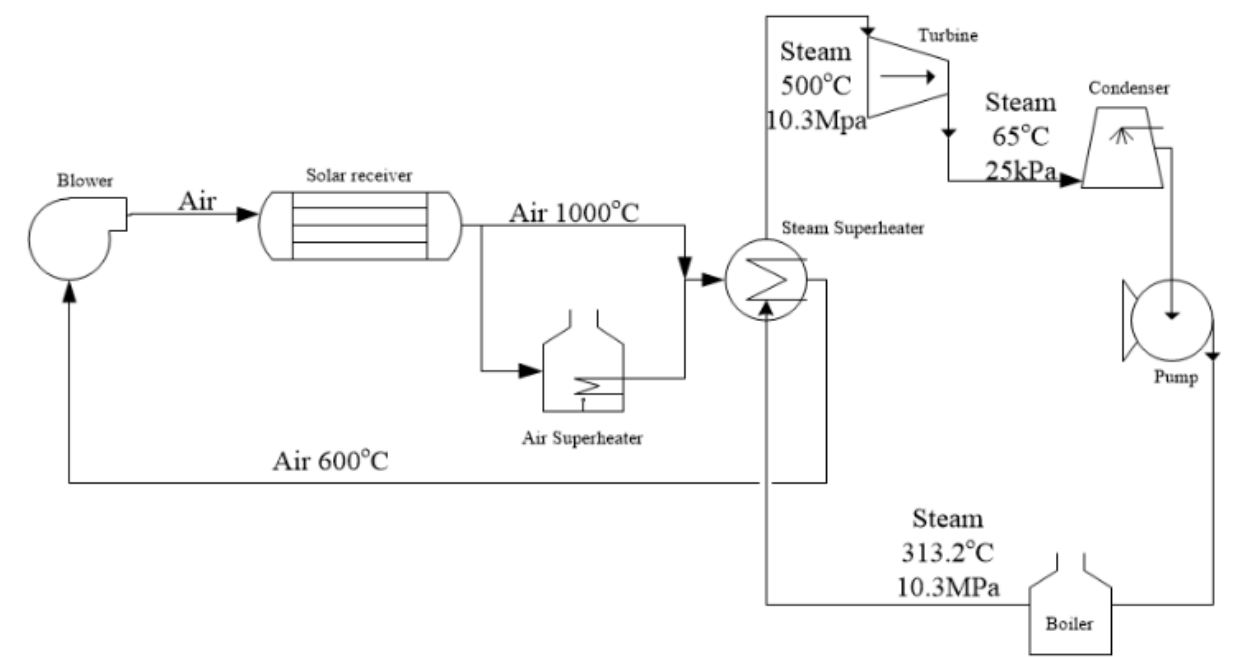

Figure 2. Solar receiver as a steam superheater. Solar energy was used to increase the temperature of steam.

The third scenario was designed (Figure 3), using solar energy to increase the temperature of steam up to $600^{\circ} \mathrm{C}$. The pressure of boiler in this scenario, was set at 22.06 MPa warranting supercritical state. However, due to this high pressure, more power is required by the pump.

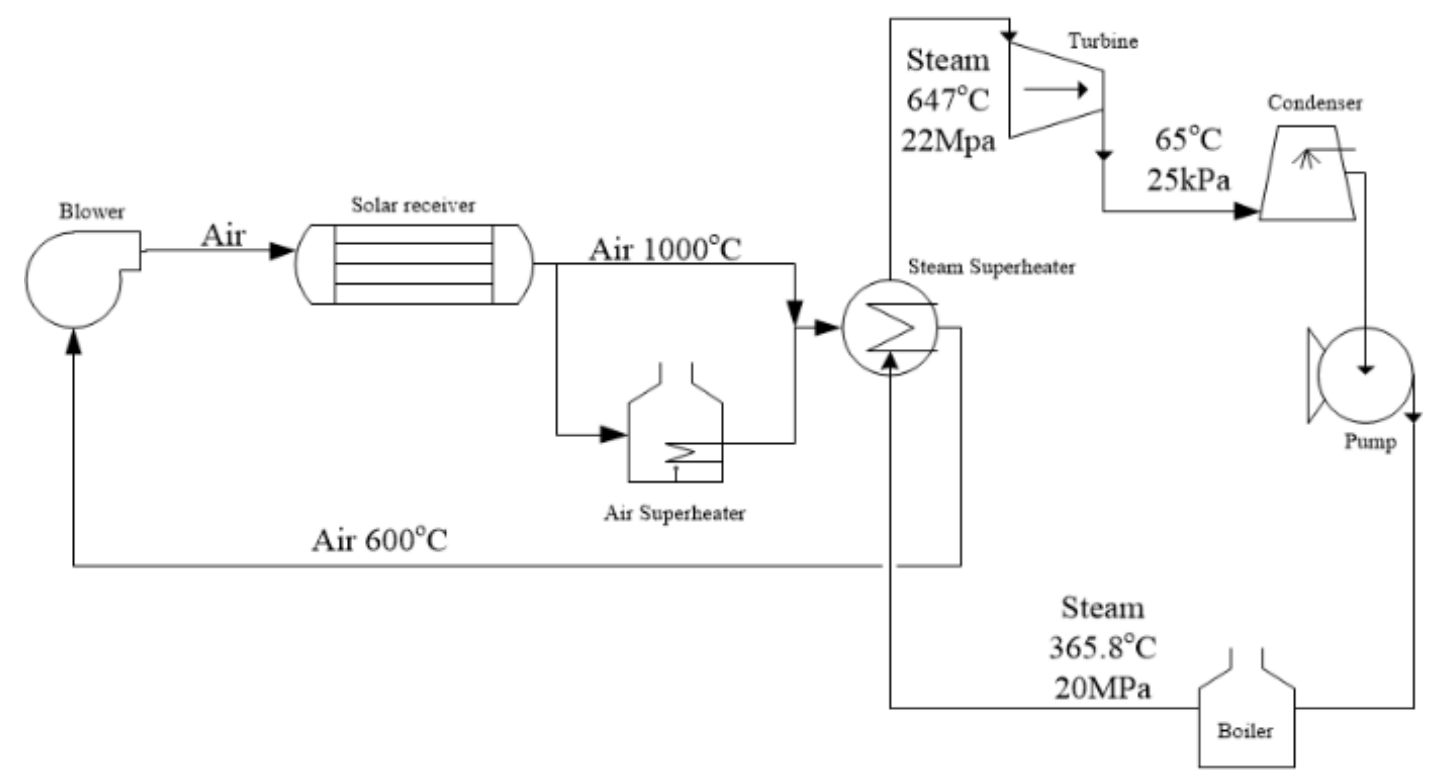

Figure 3. Supercritical steam in turbine. The solar energy was used to increase steam until supercritical temperature.

More common of the implemented designs, the forth scenario (Figure 4) works with two plants, solar plus fossil steam generator, supplying superheated steam to turbine. In this case both, boiler and solar systems, are designed to fulfill all of steam requirements. 


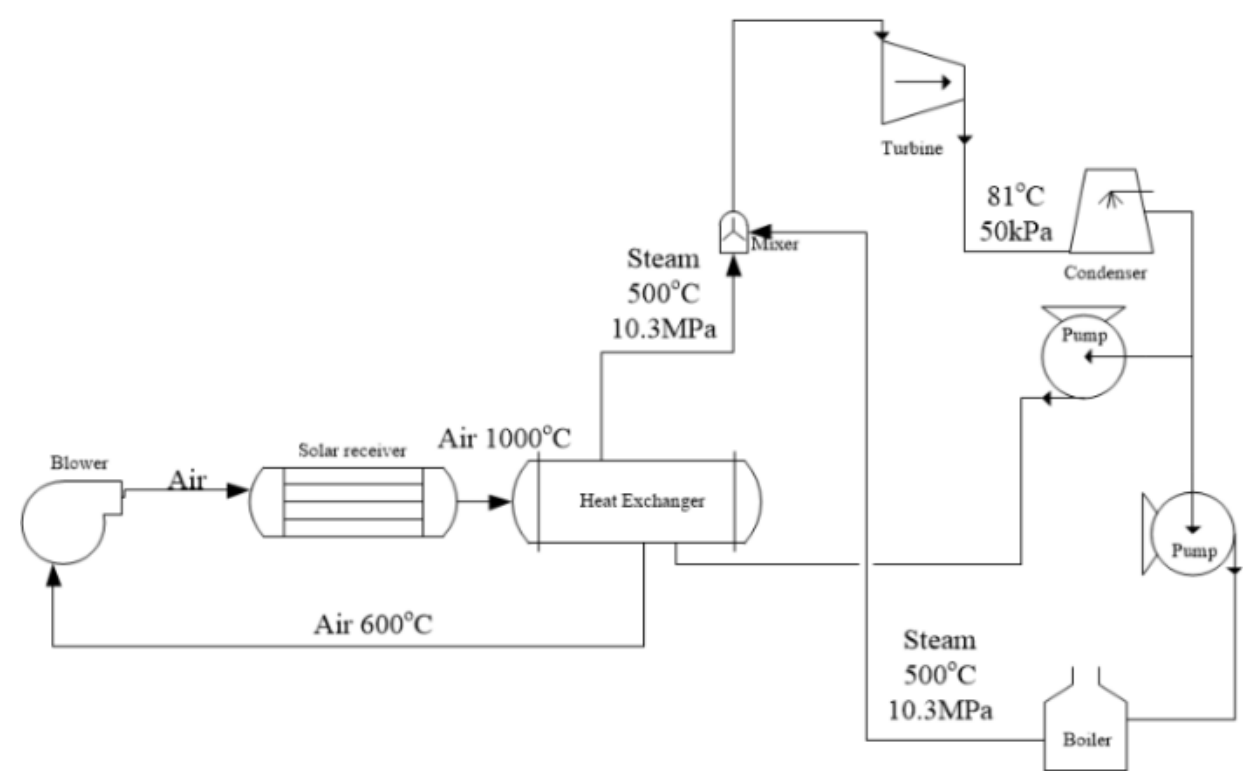

Figure 4. CSP parallel to conventional cycle using boiler. In this arrange the power plant could be operate using only solar energy or fossil fuel or both.

These configurations represent the wide range of hybridization of CSP with other fuels in a steam power plant, the focus of the present work. Other configurations are possible, such as combined cycles. However, exploring those options would disperse from the focus of this research broadening the discussion excessively. All configurations are able to provide electricity continuously at full load because of the hybridization with fossil fuel, which can supply the necessary heat in case of insufficient solar radiation. As a consequence, they can work in the electricity-distribution network base. Except for scenario 1 , the other three are able to run with solar energy alone, provided that solar radiation is sufficient.

\subsection{Economic Simulation and Analysis}

The economic viability of a power plant is a key component in deciding whether or not such a plant would be a feasible source of power. A simple Levelized Cost of Electricity (LCOE) economic model was also developed and integrated with the Hybrid CSP model in order to assess the potential economic viability of a $30 \mathrm{MW}$ power plant.

Levelized cost of electricity (LCOE) is the per-kilowatt hour cost (in real dollars) of building and operating a generating plant over an assumed financial life and duty cycle. Key inputs to calculating LCOE include capital costs, fuel costs, fixed and variable operations and maintenance $(\mathrm{O} \& \mathrm{M})$ costs, financing costs, and an assumed utilization rate for each plant type. The equation 1 below describes how to calculate it. 
$\mathrm{LCOE}=\frac{\sum_{t=1}^{n} \frac{I_{t}+M_{t}+F_{t}}{(1+\mathrm{r})^{t}}}{\sum_{k=0}^{n} \frac{E_{t}}{(1+\mathrm{r})^{t}}}$

Where: $L C O E$ is the average lifetime levelized cost of electricity generation; $I_{t}=$ investment expenditures in the year $t ; M_{t}=$ operations and maintenance expenditures in the year $t ; F_{t}=$ fuel expenditures in the year $t ; E_{t}=$ electricity generation in the year $t ; r=$ discount rate; and $n=$ life of the system.

The $L C O E$ depends primarily on capital costs and the local solar resource. In Brazil there is no actual data for the CSP technology cost. Moreover, until the auction for CSP technology is done in Brazil, it is not possible know the price for electricity. However, based on the values proposed in the work of (BIANCHINI, 2013), we were able to simulate the economic viability for three cities using SAM, where scenario for CSP power tower direct steam PPA partnership flip with debt (utility) is selected.

Power purchase agreement (PPA) projects are usually utility-scale projects and sell electricity at a price negotiated to meet a set of equity returns requirements, and may involve one or two parties.

SAM provides options for calculating a power purchase price given a target internal rate of return, or for calculating the rate of return given a power purchase price. Based on the values proposed in the work of (BIANCHINI, 2013), 15\% was used as a given target internal rate of return.

Table 1 shows the values imputed in the SAM (NREL; LLC; DOE, 2015) to simulation.

Table 1. Input values used for the SAM simulation

\begin{tabular}{|l|l|l|l|}
\hline Inputs & Values & Inputs & Values \\
\hline $\begin{array}{l}\text { Period of } \\
\text { analysis }\end{array}$ & $30^{\mathrm{b}}$ & IRR target year & $10^{\mathrm{b}}$ \\
\hline Inflation & $0 \%$ & Contingency & $10 \%$ \\
\hline $\begin{array}{l}\text { Real discount } \\
\text { rate }\end{array}$ & $10 \%$ & Land cost & $5000^{\mathrm{c}}$ \\
\hline Federal tax & $34 \%$ & $\begin{array}{l}\text { Turbine gross } \\
\text { output }\end{array}$ & $30 \mathrm{MWe}$ \\
\hline State tax & $7 \%$ & $\begin{array}{l}\text { Cycle } \\
\text { efficiency }\end{array}$ & $41.2 \%$ \\
\hline
\end{tabular}




\begin{tabular}{|c|c|c|c|}
\hline Sale rate & $5 \%{ }^{a}$ & $\begin{array}{l}\text { Turbine inlet } \\
\text { pressure }\end{array}$ & 103.4 bar \\
\hline Insurance & $0,5 \%^{\mathrm{a}}$ & $\begin{array}{l}\text { High outlet } \\
\text { pressure }\end{array}$ & 20 bar \\
\hline Debt percent & $70 \%^{a}$ & $\begin{array}{l}\text { Boiler LHV } \\
\text { efficiency }\end{array}$ & $90 \%$ \\
\hline Interest rate & $7,40 \%$ & Condenser type & Evaporative \\
\hline $\begin{array}{l}\text { Amortization } \\
\text { time }\end{array}$ & $16^{\mathrm{b}}$ & $\begin{array}{l}\text { Ambient } \\
\text { temperature }\end{array}$ & $30^{\circ} \mathrm{C}$ \\
\hline IRR target & $15 \%$ & $\begin{array}{l}\text { Fossil dispatch } \\
\text { mode }\end{array}$ & $\begin{array}{l}\text { Suplemental } \\
\text { operation }\end{array}$ \\
\hline
\end{tabular}

\subsection{Thermodynamic Cycle}

In order to find the best scenario, simulations were performed with scenarios shown in 3.1, using CyclePad software. The metrics measured for the whole cycle are described next.

Thermal efficiency $\eta_{t}$ : defined as the ratio of net power output to total thermal energy input, it is therefore a measure of how much we can convert.

$\eta_{t}=\frac{\dot{W}_{n e t}}{\dot{Q}_{i n}}$

where

$\dot{W}_{\text {net }}=\dot{W}_{\text {in }}+\dot{W}_{\text {out }}$,

and

$\dot{Q}_{\text {in }}=\dot{Q}_{\text {boiler }}+\dot{Q}_{C S P}$

Maximum and minimum temperatures and pressures for the cycle: $T_{\max }, T_{\min }, P_{\max }$ and $P_{\text {min }}$;

Steam mass flow $\dot{m}$, which determine the size of power plant;

Back work ratio $\eta_{W}$ : measures the cycle efficiency by examining the net work needed to power the cycle as a fraction of the total positive work generated by the working-producing components in the cycle

$\eta_{W}=\frac{-\dot{W}_{\text {in }}}{\dot{W}_{\text {out }}}$ 
Work ratio $\bar{w}$ : is a measure of the power that the cycle must consume internally to maintain fluid flows and pressures. In Rankine cycle, which condenses its working fluid, the work-ratio will be very high because pumping liquids requires relatively little energy

$$
\bar{w}=\frac{\dot{W}_{\text {net }}}{\dot{W}_{\text {out }}} ;
$$

Net heat flow $\dot{Q}_{\text {net }}$ : the heat flowing into the cycle less the heat flow out of the cycle. By the second law of thermodynamics, there must be a heat-flow out of cycle, since all cycles must operate between high and low temperature reservoirs. The sign convention results in heat outflows being negative, hence the addition in this equation

$\dot{Q}_{\text {net }}=\dot{Q}_{\text {in }}+\dot{Q}_{\text {out }}$.

\section{Results and Discussions}

A hybrid solar thermoelectric plant of $30 \mathrm{MW}$ connected to the Brazilian distribution network was defined as the common configuration set. The system will have hybrid operation, using fossil fuel boiler and complementary heliothermic heat source. The power plant was set in accordance to Brazilian legislation, which grants a tax relief for electricity production plants with capacity below $30 \mathrm{MW}$.

\subsection{Simulation of Thermodynamic Cycle}

To compare different arrangements, the same configuration set were used for all scenarios: turbine gross output close to $30 \mathrm{MWe}$, isentropic efficiency $\eta_{S}=75 \%$, working with same inlet pressure $P_{\text {in }}=10.3 \mathrm{MPa}$ and outlet pressure $P_{\text {out }}=25 \mathrm{kPa}$ except in scenario using supercritical steam where $P_{\text {in }}=20 \mathrm{MPa}$. Figure 5 represents the $T S$ diagram of scenario 1 .

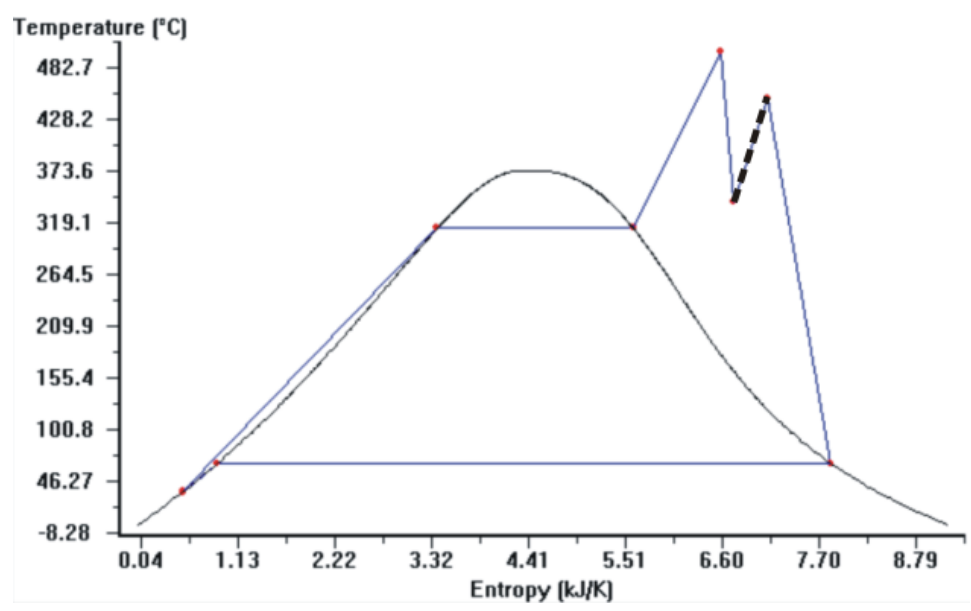


Figure 5. T S diagram to scenario 1 - using solar energy to reheat steam. Thick black dashed line represents the process where solar thermal energy is used.

When solar energy is used to superheat steam, or in a parallel plant, as described in scenarios 2 and 4 respectively, they can be represented by diagram of figure 6 .

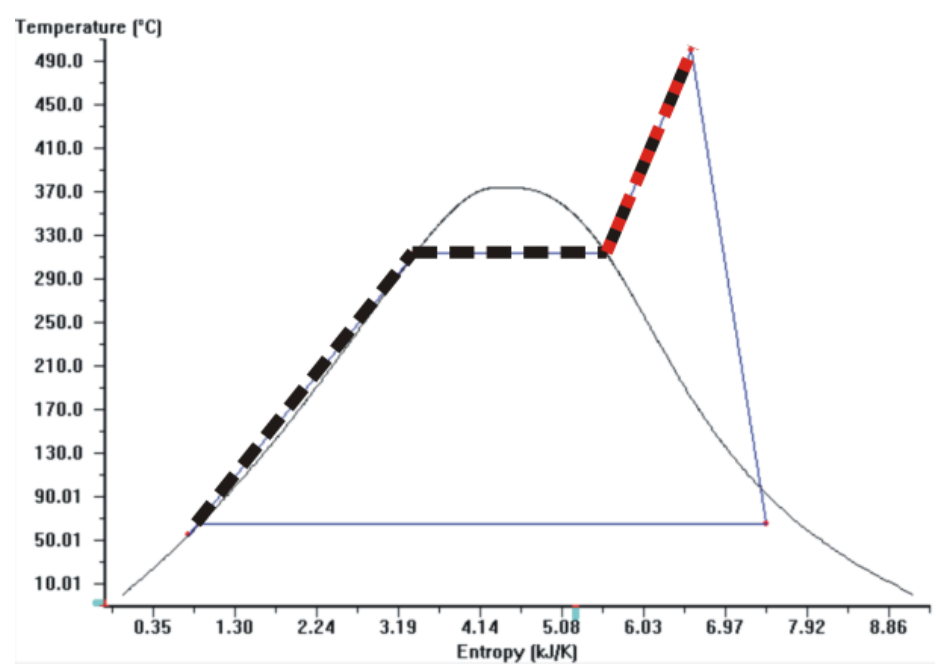

Figure 6. Tx S diagram to scenarios 2 and 4 - using solar energy to superheat steam or in a parallel plant. Thick dotted red and dashed black lines represent the processes where solar thermal energy are used for scenario 2 and 4 respectively.

If the steam is heated to supercritical state, as designed in scenario 3, the TS diagram is represented by Figure 7.

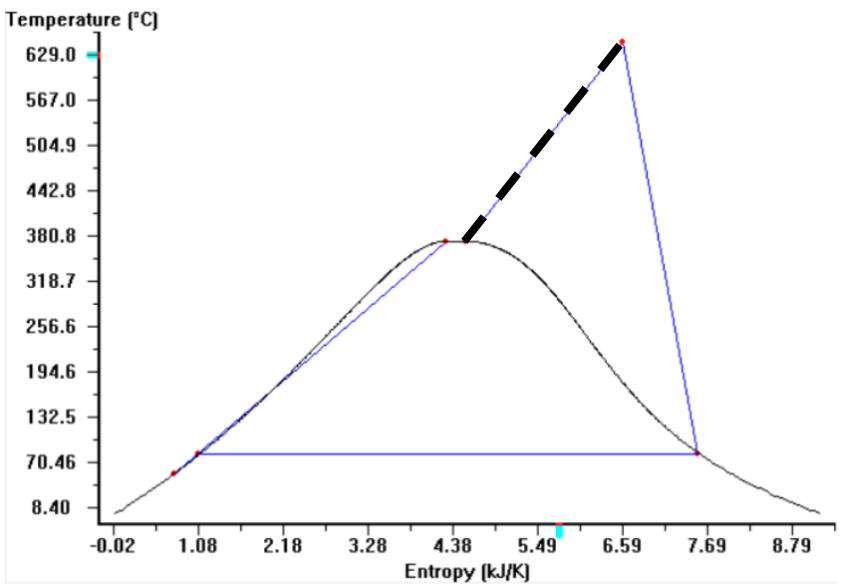

Figure 7. T x S diagram to scenario 3 - using solar energy to increase temperature of steam up to supercritical state. Thick black dashed line represents the process where solar thermal energy is used. 


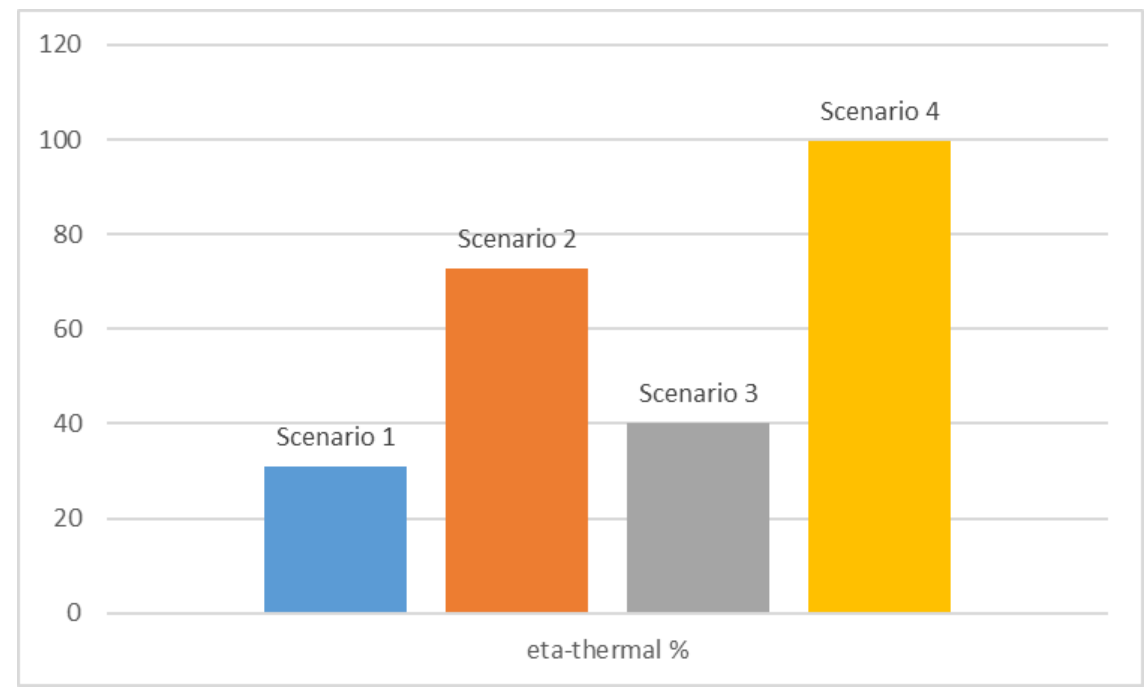

Figure 8. Efficiency of each scenario at maximum solar radiation

In scenario 4, the control of amount of steam is produced by boiler is made by solar availability. The graph of Figure 9, shows the influence of solar radiation level in the plant efficiency. Note when solar energy is sufficient (boiler working under 40\%) no fossil fuel fuel is needed.

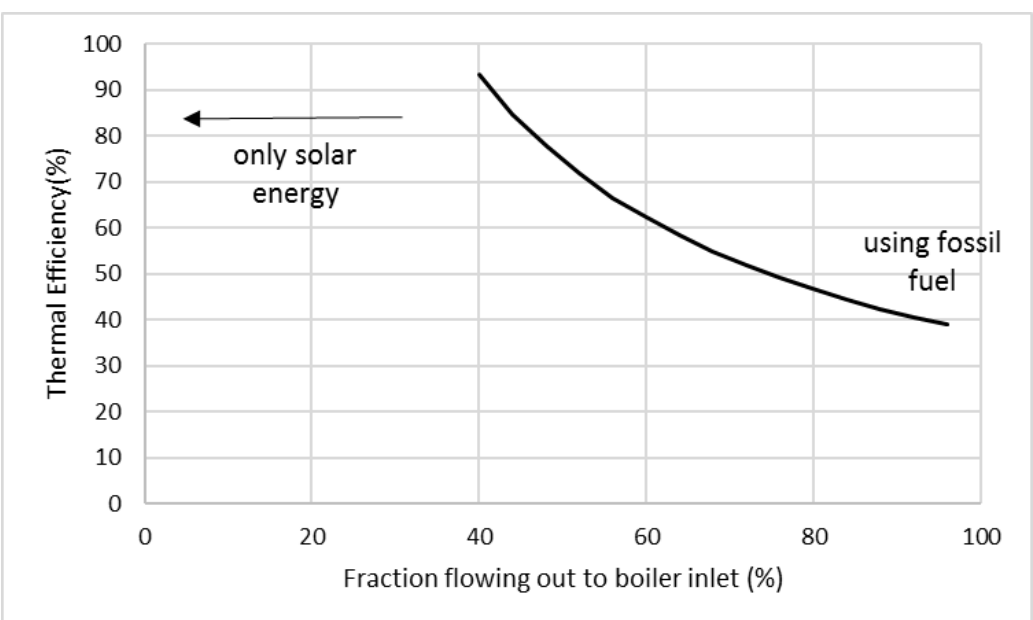

Figure 9. Thermal efficiency in function of solar irradiation availability

Table 2 shows the consolidation of simulations results. In scenario 1 does not have a good efficiency, comparatively to others (Figure 8), due the energy needed to reheat the steam is lower than the energy used in boiler in the first part of design, which uses fossil fuel.

Table 2. Consolidation of thermodynamic simulation.

\begin{tabular}{|c|c|c|c|c|}
\hline Parameter & Sc. 1 & Sc. 2 & Sc. 3 & Sc. 4 \\
\hline$\eta_{\text {Carnot }}(\%)$ & 75,8 & 74,69 & 75,8 & 74,27 \\
\hline$\eta_{\text {thermal }}(\%)$ & 30,92 & 72,68 & 40,03 & NA \\
\hline$T_{\max }\left({ }^{\circ} \mathrm{C}\right)$ & 1.000 & 1.000 & 1.000 & 1.000 \\
\hline
\end{tabular}




\begin{tabular}{|c|c|c|c|c|}
\hline$T_{\min }\left({ }^{\circ} \mathrm{C}\right)$ & 35 & 49,1 & 35 & 54,47 \\
\hline$P_{\max }(\mathrm{kPa})$ & 10.300 & 10.300 & 20.000 & 10.342 \\
\hline$P_{\min }(\mathrm{kPa})$ & 25 & 25 & 25 & 25 \\
\hline Power in $(\mathrm{kW})$ & $-309,6$ & $-175,4$ & $-680,8$ & $-224,5$ \\
\hline Power out $(\mathrm{kW})$ & 30.119 & 29.972 & 31.256 & 29.979 \\
\hline net - power $(\mathrm{kW})$ & 29.810 & 29.796 & 30.575 & 29.754 \\
\hline back-work - ratio $(\%)$ & 1,03 & 0,5852 & 2 & 0,7487 \\
\hline work - ratio $(\%)$ & 98,97 & 99,41 & 97,82 & 99,25 \\
\hline$\dot{Q}_{\text {in }}(\mathrm{kW})$ & 96.399 & 40.996 & 76.383 & 57.520 \\
\hline$\dot{Q}_{\text {out }}(\mathrm{kW})$ & -74.100 & -77.500 & -84.007 & -76.764 \\
\hline$\dot{Q}_{\text {net }}(\mathrm{kW})$ & 22.299 & -36.504 & -7.624 & -19.244 \\
\hline Air flow $(\mathrm{kg} / \mathrm{s})$ & 19 & 165 & 95 & 191 \\
\hline Steam flow $(\mathrm{kg} / \mathrm{s})$ & 30 & 34 & 34 & 34 \\
\hline
\end{tabular}

NA - Not applicable. In this condition no fossil fuel is needed.

* This efficiency refers to total energy generated divided by energy supplied by fuel

The thermal efficiency presented in Table 2 refers to electric energy generated by each energy-unit supplied by the fossil fuel. In this case, higher efficiency is obtained with a higher solar contribution to the system. Analyzing the scenario 2 is possible to note that without heat storage, it is not feasible. Although the high thermal efficiency is obtained at maximum solar radiation, shown in figure 8 , variations of solar resource must be compensated by fossil fuel. Nevertheless, the scenario 4 presents the better performance in both, in maximum irradiance (Figure 8) and working together to fossil fuel (Figure 9).

In this scenario 3, the energy spent to increase the temperature to supercritical state, sourced by solar (38 MW), is lower than energy spent in boiler (76 MW). The high pressure in boiler $(20 \mathrm{MPa})$ is the main reason for this efficiency gap between scenarios 2 and 3.

The scenario 4 was the more efficient than others, presenting without consume of fossil fuel in maximum solar irradiance.

\subsection{Site Selection}

Three locations were selected for this investigation based on solar irradiation data. Three cities were chosen in the higher incidence area of direct normal radiation in Brazil (Figure 10): Santa Maria da Vitoria - BA (SMV), Porto Nacional - TO (PN), and Brasília DF (BSB). 


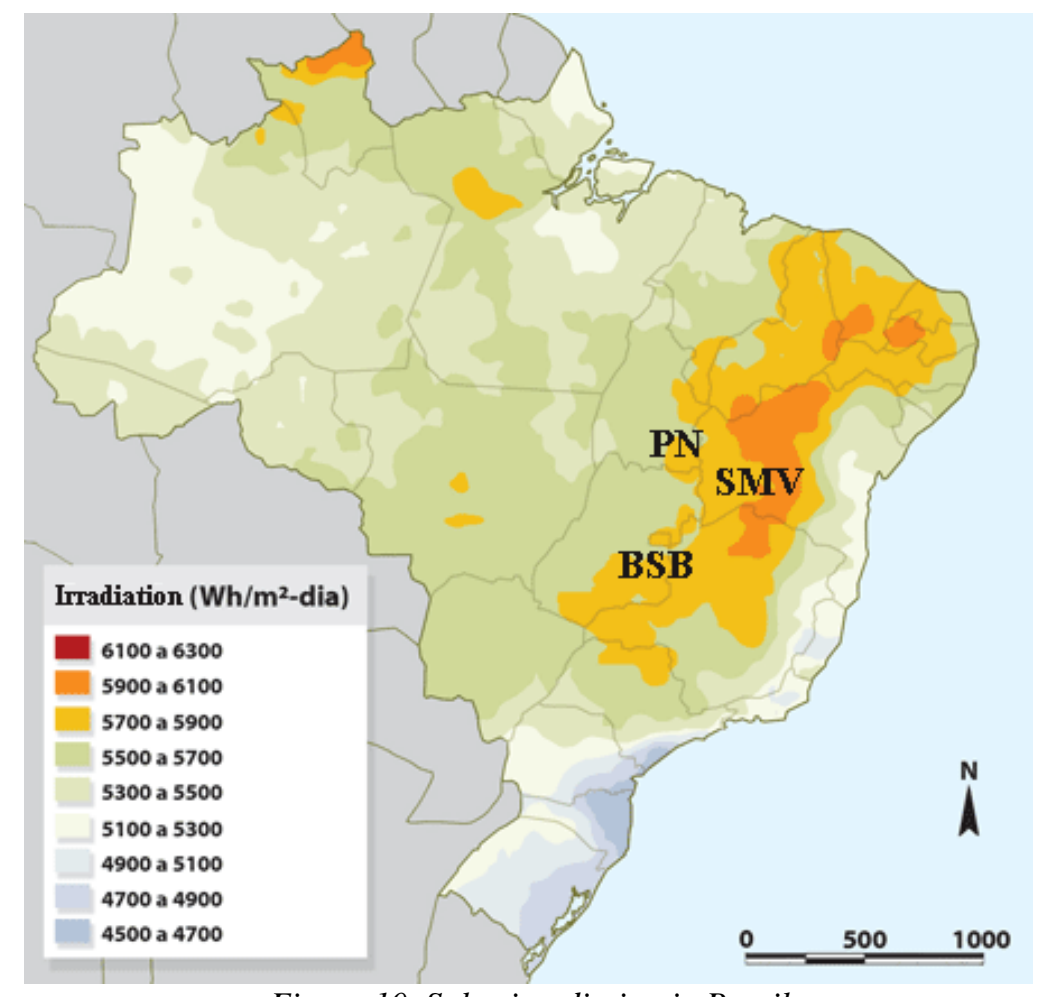

Figure 10. Solar irradiation in Brazil Source: NASA

The incidence of solar radiation city was compared in order to verify monthly variability of solar radiation profile at each location (Figure 11). It is interesting to notice that, besides differences in mean radiation levels, variability also differs for the three cities. PN has the highest peak value and highest variability. Meanwhile, SMV maintains high levels of DNI throughout the year.

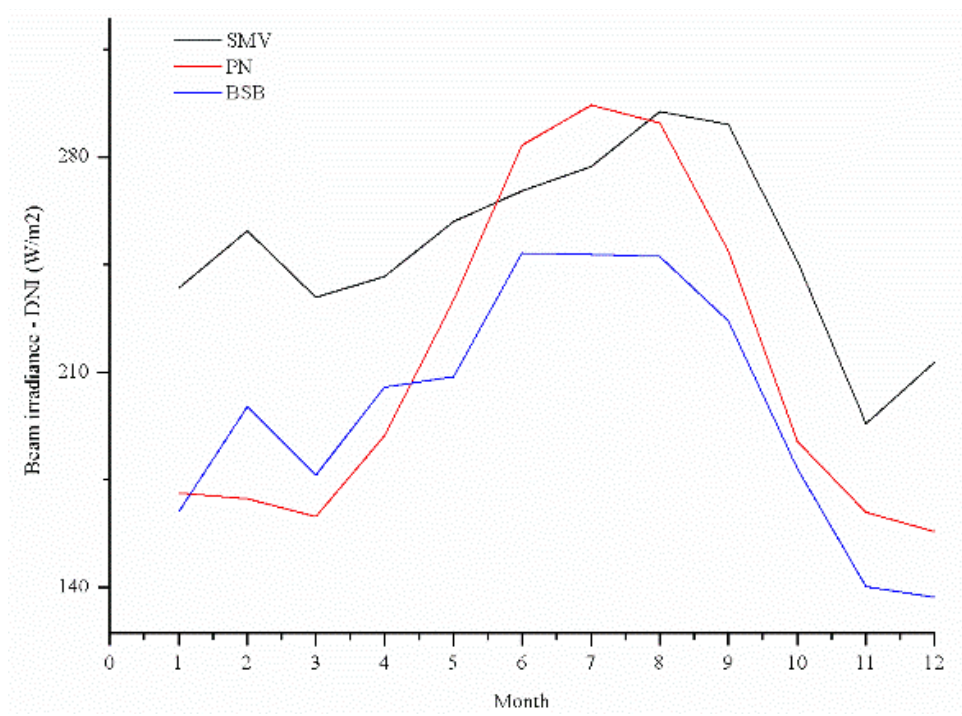

Figure 11. Mean irradiation (DNI) in the cities. Source: SWERA(2015)

Finally, the cumulative beam irradiance was compared, showing SMV as the city with the highest DNI among the three studied. 


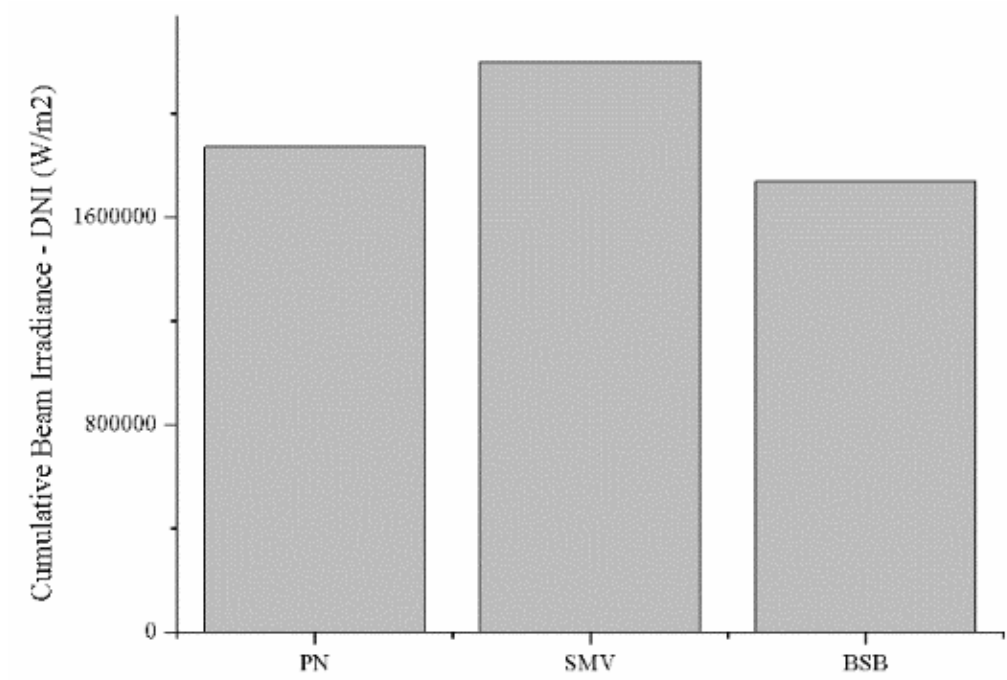

Figure 12. Cumulative bean irradiance by cities

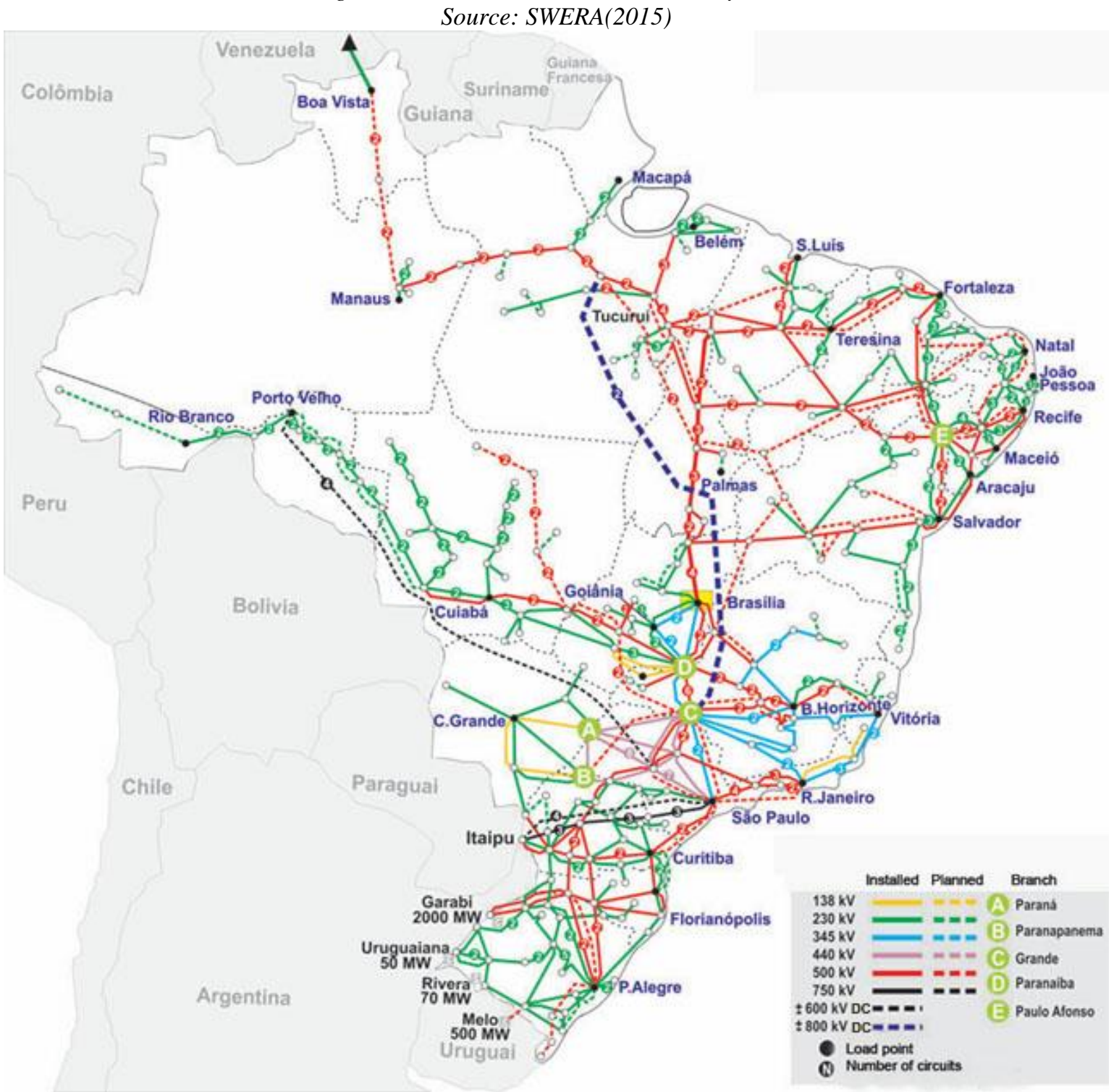

Figure 13. Transmission lines in Brazil. Source: Aneel 2015 
In order to choose the city, three metrics were analyzed: distance to transmission lines (Figure 13), direct normal irradiation (DNI) (Figures 11 and 12) and economic feasibility. Additionally, SAM software was used to operational simulation as follows.

\subsection{Operational and economic feasibility simulation}

Using data listed in able 1, the configuration set of scenario 4 and solar resource showed in 4.2, simulations were performed for economics and operational conditions for each city. The results are shown in table 2 below.

Table 3. The results of simulation for three cities in Brazil.

\begin{tabular}{|l|c|c|c|}
\hline Metric & \multicolumn{1}{|l|}{ SMV } & \multicolumn{1}{l|}{ BSB } & PN \\
\hline Annual energy (GWh) & 57.6 & 41.2 & 40.7 \\
\hline Capacity factor (\%) & 24.4 & 17.4 & 17.2 \\
\hline Levelized PPA price (nominal) ( $\varnothing \mathrm{kWh})$ & 60.42 & 83.85 & 86.57 \\
\hline Levelized cost (nominal) ( $\varnothing \mathrm{kWh})$ & 38.10 & 53.74 & 54.51 \\
\hline Investor IRR (after-tax) (\%) & 15.73 & 15.64 & 15.73 \\
\hline Investor NPV (after-tax) (M US\$) & 18.4 & 24.6 & 18.6 \\
\hline Developer NPV (after-tax) (M US\$) & 106.3 & 109.7 & 107.8 \\
\hline Initial cost (M US\$) & 205.6 & 202.1 & 208.7 \\
\hline Equity (M US\$) & 74.5 & 73.2 & 75.6 \\
\hline Debt (US\$) & 131.1 & 128.9 & 133.1 \\
\hline Minimum DSCR & 2.23 & 2.16 & 2.23 \\
\hline
\end{tabular}

Results presented in the table 2, reveal Santa Maria da Vitória (SMV) as the most attractive region to install a hybrid solar thermoelectric. The difference in solar resource in SMV was the main factor for this selection, where it is $8 \%$ higher than BSB and $6 \%$ higher than PN. The consequence is up to $29 \%$ more energy produced in a year, better capacity factor, and low cost of produced energy. The costs of implementation are basically the same, because the tax and land costs do not have great differences. The financial costs were considered equal in the three states studied: Federal district, Tocantins and Bahia. As a consequence, all metrics related to financial market and return of investments was similar.

All of these three cities are close to the Brazilian electric power distribution net, and then connection costs were low. 
The CSP technology configuration suggested by SAM optimization procedure was a solar tower with $136.3 \mathrm{~m}$ of height, using a receiver with $10.5 \mathrm{~m}$ of diameter, $15.5 \mathrm{~m}$ of height and 12 panels. To thermal design and operation, it has $109 \mathrm{M} W_{t h}$ of thermal power, with 1.5 of solar multiple. This simulated plant works without storage and the backup is made by fossil fuel in parallel to solar.

To install the solar field are needed 151 acres $\left(611 \times 10^{3} \mathrm{~m}^{2}\right)$, where each heliostat has $139.7 \mathrm{~m} 2$ positioned like the figure 14 below

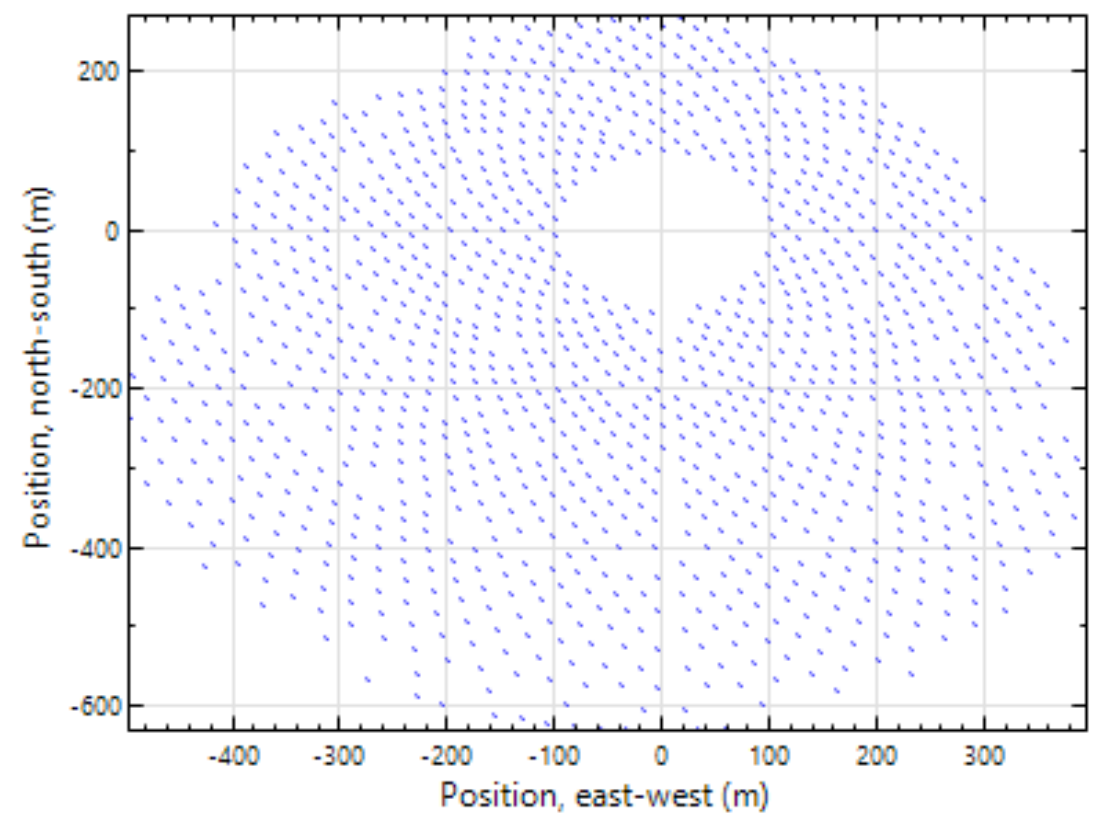

Figure 14. Solar field showing the positioning of heliostats.

\section{Conclusions}

Simulations were performed for four different configurations of hybrid solar-fossil fuel power plants. In all cases air was used as HTF. In the cases simulated, it was possible to conclude that the better scenario for hybrid thermoelectric power plant is the one represented by scenario 4 . When the maximum solar irradiation is available, there is no need to burn fossil fuel with configurations represented by scenarios 2, 3 and 4 .

To choose the city to install the power plant, solar atlas with satellite data was used. By the data, the best city amongst the ones used in the simulations, Santa Maria da Vitoria BA provided best results, generating up to $29 \%$ more electricity than other cities studied, operating with lower cost than others, consequence of its good DNI and proximity to the Brazilian electric power distribution net. 
The CSP technology suggested for use in this case is the solar tower, with 1.5 of solar multiple. This simulated plant works without storage and the backup is made by fossil fuel in parallel to solar.

151 acres are needed to install this design including solar tower and utilities buildings. Comparing to a hydroelectric power plant, which would require around 741 acres, this area is somewhat modest with reduced environmental impacts.

\section{Acknowledgements:}

Fabio Lisboa is supported by FAPEAM - HR PhD program and Mario Siqueira's contribution is supported by CNPq, project number 407076/2013-1.

\section{Nomenclature}

$\dot{Q}_{\text {in }}$ - Inlet heat flow $\left[M W_{t}\right]$

$\dot{W}_{\text {in }}$ - Inlet power $\left[M W_{e}\right]$

$\dot{Q}_{n e t}$ - Net heat flow $\left[M W_{t}\right]$

$\dot{W}_{n e t}-$ Net power $\left[M W_{e}\right]$

$\dot{Q}_{\text {out }}$ - Outlet heat flow $\left[M W_{t}\right]$

$\dot{W}_{\text {out }}$ - Outlet power $\left[M W_{e}\right]$

$\dot{m}$ - Steam mass flow $\left[\mathrm{kg} \mathrm{s}^{-1}\right.$ ]

$E_{t}$ - Electricity generation in the time [MWh]

$F_{t}$ - Fuel expenditures in the time [US\$]

$I_{t}$ - Investment expenditures in the time [US\$]

$M_{t}$ - Operations and maintenance expenditures [US\$]

$\bar{w}-$ Work ratio $[\%]$

$\eta_{W}$ - Back work ratio [\%]

$\eta_{t}$ - Thermal efficiency [\%]

BS - Backup System

CRS - Central Receiver System

CSP - Concentrated Solar Power Plant

HTF - Heat transfer fluid

ISCC - Integrated solar combined cycle plants 
LFR - Linear Fresnel Reflector

PDC - Parabolic Dish Collectors

PPA - Power purchase agreement

PTC - Parabolic Trough Collector

SPT - Solar Power Tower

TES - Thermal Energy Storage system

LCOE - Levelized Cost of Electricity [ $\varnothing \mathrm{kWh}]$

$P$ - Pressure $[\mathrm{kPa}]$

$T$ - Temperature $\left[{ }^{\circ} \mathrm{C}\right]$

$n$ - Life of the system [year]

$r$ - Discount rate [\%]

$t$ - Time [year]

\section{References:}

BARLEV, D.; VIDU, R.; STROEVE, P. Innovation in concentrated solar power. Solar Energy Materials and Solar Cells, v. 95, n. 10, p. 2703-2725, 2011.

BIANCHINI, H. M. Avaliação comparativa de sistemas de energia solar térmicaUniversidade Federal do Rio de Janeiro, , 2013.

BURIN, E. K. et al. Boosting power output of a sugarcane bagasse cogeneration plant using parabolic trough collectors in a feedwater heating scheme. Applied Energy, v. 154, p. 232-241, 2015.

COELHO, B. et al. Biomass and central receiver system (CRS) hybridization: volumetric air CRS and integration of a biomass waste direct burning boiler on steam cycle. Solar energy, v. 86, n. 10, p. 2912-2922, 2012.

DUNN, R. et al. An experimental study of ammonia receiver geometries for dish concentrators. Journal of Solar Energy Engineering, v. 134, n. 4, p. 41007, 2012.

EMTE, C.; AMBIENTE, M. TERMOSOLAR BORGES : A THERMOSOLAR HYBRID PLANT WITH. n. November, 2010.

FORBUS, K. D.; WHALLEY, P. B. CyclePad, 1995. Disponível em: <http://www.qrg.nwu.edu/software.htm> GOSWAMI, D. Y.; KREITH, F.; KREIDER, J. F. Principles of solar engineering. [s.1.] 
CRC Press, 2000.

LLORENTE, I.; ÁLVAREZ, J.; BLANCO, D. Performance model for parabolic trough solar thermal power plants with thermal storage: Comparison to operating data. Sol. Energy, v. 85, n. 10, p. 2443-2460, 2001.

MCGOVERN, R. K.; SMITH, W. J. Optimal concentration and temperatures of solar thermal power plants. Energy Conversion and Management, v. 60, p. 226-232, 2012. MÜLLER-STEINHAGEN, H.; TRIEB, F. Concentrating solar power. A review of the technology. Ingenia Inform QR Acad Eng, v. 18, p. 43-50, 2004.

NREL, N. R. E. L.; LLC, A. FOR S. E.; DOE, U. S. D. O. E. System Advisor Model (SAM)USA, 2015.

PERLACK, R. D. et al. Biomass as feedstock for a bioenergy and bioproducts industry: the technical feasibility of a billion-ton annual supply. [s.1.] DTIC Document, 2005.

PETERSEIM, J. H. et al. Concentrating solar power hybrid plants e Enabling cost effective synergies. Renewable Energy, v. 67, p. 178-185, 2014.

PITZ-PAAL, R. ECOSTAR: European Concentrated Solar Thermal Road-Mapping; Roadmap Document (WP 3 Deliverable No. 7). [s.1.] DLR, 2005.

PY, X.; AZOUMAH, Y.; OLIVES, R. Concentrated solar power: Current technologies, major innovative issues and applicability to West African countries. Renewable and Sustainable Energy Reviews, v. 18, p. 306-315, 2013.

ROMERO-ALVAREZ, M.; ZARZA, E. Concentrating Solar Thermal Power-Energy ConversionCRC Press, Taylor \& Francis Group, , 2007.

SARGENT, L. Assessment of parabolic through and power tower solar technology cost and performance forecasts (final). Chicago: SL-5641, 2003.

SORIA, R. et al. Hybrid concentrated solar power (CSP)-biomass plants in a semiarid region: A strategy for CSP deployment in Brazil. Energy Policy, v. 86, n. March 2014, p. 57-72, 2015.

ZHANG, H. L. et al. Concentrated solar power plants: Review and design methodology. Renewable and Sustainable Energy Reviews, v. 22, p. 466-481, jun. 2013a. ZHANG, H. L. et al. Concentrated solar power plants: Review and design methodology. 
Renewable and Sustainable Energy Reviews, v. 22, p. 466-481, jun. 2013 b.

ZOSCHAK, R. J.; WU, S. F. Studies of the direct input of solar energy to a fossil-fueled central station steam power plant. Solar Energy, v. 17, n. 5, p. 297-305, 1975. 